\title{
Publisher Correction: A space-time tradeoff for implementing a function with master equation dynamics
}

\author{
David H. Wolpert (10 ${ }^{1,2}$, Artemy Kolchinsky ${ }^{1}$ \& Jeremy A. Owen ${ }^{3}$
}

Correction to: Nature Communications https://doi.org/10.1038/s41467-019-09542-x, published online 15 April 2019.

The original version of the Supplementary Information associated with this Article contained an error throughout, in which all inline references to Theorems, Definitions, and Lemmas given in the main Article were incorrectly given as '??'. The HTML has been updated to include a corrected version of the Supplementary Information.

Published online: 01 May 2019

\begin{abstract}
(c) (i) Open Access This article is licensed under a Creative Commons Attribution 4.0 International License, which permits use, sharing, adaptation, distribution and reproduction in any medium or format, as long as you give appropriate credit to the original author(s) and the source, provide a link to the Creative Commons license, and indicate if changes were made. The images or other third party material in this article are included in the article's Creative Commons license, unless indicated otherwise in a credit line to the material. If material is not included in the article's Creative Commons license and your intended use is not permitted by statutory regulation or exceeds the permitted use, you will need to obtain permission directly from the copyright holder. To view a copy of this license, visit http://creativecommons.org/licenses/by/4.0/.
\end{abstract}

(C) The Author(s) 2019

\footnotetext{
${ }^{1}$ Santa Fe Institute, 1399 Hyde Park Road, Santa Fe, NM 87501, USA. ${ }^{2}$ Arizona State University, Tempe 85281 AZ, USA. ${ }^{3}$ Physics of Living Systems Group, Department of Physics, Massachusetts Institute of Technology, 400 Tech Square, Cambridge, MA 02139, USA. Correspondence and requests for materials should be addressed to D.H.W. (email: dhw@santafe.edu)
} 